\title{
Learning and Study Strategies: Academic Achievement and Gender Differences
}

\author{
Beena Daliya $R^{*}$ and Sudha Bhogle ${ }^{\dagger}$
}

\section{Abstract}

To do well in school and for enhanced academic success, effective Learning and Study strategies are important. The objectives of this research work were to determine gender differences, if any, in Learning and Study strategies in high school students and to find the relationship between these strategies and Academic achievement.

To do this, Learning and Study Strategies Inventory (LASSI) - Weinstein \& Palmer, (2002) was administered to a group of $684,8^{\text {th }}$ std., school students, of which 363 were boys and 321 were girls. These students were selected from private schools of Bangalore; all the 4 zones - north, south, east, and west - were represented. All the students chosen were studying the state syllabus.

The results of the research indicate gender differences in the following strategies - processing of information, motivation and selection of main ideas. No gender differences emerged for Academic achievement. Further, academic achievement was found to be significantly related to levels of anxiety, attitude, concentration ability, selection of main ideas, effective time management and test taking strategies.

Keywords: Learning strategies, Study strategies, Academic Achievement, Gender difference.

* Research Scholar, Department of Psychology, Bangalore University, Bangalore India; beenadaliya15@gmail.com

† Head, educafé, Bangalore, India: bhogle@gmail.com 


\section{Introduction}

Education provides considerable value to individuals; it helps each individual to make of himself all that is possible for him to become. Good academic performance and high percentages in examinations are often considered as predictors of academic success. To perform well in examinations and for enhanced academic success, effective study skills comprising learning techniques and study strategies have been found to play an important role.

Study skills: have been defined as the successful use of techniques and methods suitable for carrying out a learning task (Gall, 1990). It implies that any student who has efficient study skills can effectively and appropriately use them and master the learning task. Students with ineffective and poor study skills will fail on a similar learning task because of unsuitable strategies or for using the appropriate strategy in an unsuccessful style. Study skills play an important role because they help students learn and improve their academic performance. They help students to become increasingly independent learners, which is an essential feature at higher levels of studies. If students do not develop effective study strategies and techniques, they may be unable to respond appropriately to the opportunities and expectations that arise at the different levels of education.

Research in the use of learning strategies on academic achievement has shown that students do not voluntarily display or learn effective study skills unless they are explicitly given the information and instruction for their use. Systematic training is therefore the need of the hour if students have to learn and apply these skills to enhance academic achievement. Review of research in this area has explicitly brought out the importance of Learning and Study strategies for academic performance.

Synder (2000) analyzed the relationships among multiple intelligence, learning styles and Academic/scholastic achievement in 128 higher secondary school students. The analysis revealed that $81 \%$ of the students were tactile learners who needed hands-on experience and learnt by doing things and putting them into action rather than just hearing, watching or listening. $64 \%$ of the students 
were also global learners. A positive correlation was also found between academic achievement test scores and two types of multiple intelligences - logical and linguistic as well as one learning style - visual.

Barbara, John and Craig (1999) examined and compared study skills among 255 high school honors and college preparatory students. Findings on the Study Habits Inventory revealed that even college preparatory and the honors students showed deficiency in their study skills - only $48 \%$ of the behaviors assessed were observed. Slate et. al., (1993), had also reported similar findings. Poor study skills were evidenced even among the brightest and best students. These findings underlined the need for specific training in academic skills.

Verma's (1996) in his study tried to determine the effects of study habits on academic performance in different school courses. The study was conducted on 504 male students studying in tenth class in ten secondary schools of Delhi. Study habits and locus of control were assessed. The findings of the research indicated that the use of specific study habits had differential effects on different subjects. They appeared to play a significant role for three subjects - Hindi, English and social studies.

Yip et.al's (2005) in their study tried to examine the precise study techniques that impacted academic performance at school and college levels as well as examined if the study techniques found efficient at school level also worked at University level. A revised version of the Learning and Study Strategies Inventory (LASSI, Weinstein, Zimmermann, \& Palmer, 1987) was used. They reported significant differences between high and low school achievers, on the study strategies used. However, such differences did not emerge for University students.

Slotte, Lonka \& Ylänne (2001) conducted two studies to explore gender differences if any, in the use of spontaneous studystrategies when studying from text books. The results of both the studies revealed important and significant differences between boys and girls in the use of study strategies: girls, more often than boys, applied explicit study strategies, especially for note taking. However, no gender differences were found in comprehending 
both philosophical and statistical notes. The results seem to imply that different learning outcomes may be more a result of the use of different study strategies rather than gender per se.

Anzi \& Owayed (2005) in their study examined the correlation between academic achievement and the following variables: anxiety, self-esteem, optimism, and pessimism. 400 male and female college students constituted the sample. The results revealed positive and significant relationships between academic scores and optimism and self-esteem; and negative and significant correlations between academic achievement and anxiety and pessimism.

In their study, Lightbody et.al (1996) reported differences between males and females in rating factors leading to success in academics. Female students were seen rating hard work and teachers' liking as more important than males, and males were seen rating cleverness, talent and luck as more important than female students.

Summarizing, these research studies underline the importance of both cognitive factors such as concentration and information processing, as well as non cognitive factors such as anxiety, attitude etc on academic achievement. The use of effective study techniques is found to assist in academic performance. The use of specific study strategies difference across levels of study and between the two sexes. However, most of these studies have been conducted in the West and there is a lacuna with regard to Indian studies. Moreover, several researchers have studied college and undergraduate students. This study is an attempt to fill part of the lacuna with respect to the correlates of these variables in Indian high school students.

\section{Objectives}

To determine gender differences, if any, in Learning \& Study strategies used by Indian high school students.

- To determine the correlation between academic achievement and the different Learning \& Study strategies. 


\section{Hypotheses}

1. There will be a significant gender differences in the different Learning \& Study strategies assessed

2. Academic achievement will be significantly correlated with the different Learning and Study strategies assessed.

\section{Sample}

The sample of the study consisted of 684 students, of which 363 were boys and 321 were girls. These students were selected from private schools of Bangalore; all the 4 zones- north, south, east, and west - were represented. All the students chosen were studying $8^{\text {th }}$ std. from the state syllabus (SSLC). Table 1 gives the details of the number of students in each school.

Table 1: giving sample details

\begin{tabular}{|l|l|l|l|l|l|}
\hline S1 no & School & Region & No of Boys & No of Girls & Total \\
\hline 1 & School 1 & North & 55 & 15 & 70 \\
\hline 2 & School 2 & North & 114 & 79 & 193 \\
\hline 2 & School 3 & South & 137 & 32 & 169 \\
\hline 3 & School 4 & East & 57 & 27 & 84 \\
\hline 5 & School 5 & West & 00 & 168 & 168 \\
\hline Total & & 363 & 321 & 684 \\
\hline
\end{tabular}

The mean age of the sample was 13.18 years [SD $=0.58$ ] for boys and 13.27 years [SD $=0.57$ ] for girls. Order of birth indicated that $38.5 \%$ were first borns, $32.4 \%$ were 'last' born, and $8.9 \%$ were 'only' children

\section{Tools}

Given below is the description of tools administered for the study:

Socio demographic data sheet: A personal data sheet was developed to elicit demographic details relevant to the study. Marks in the last examination were obtained as an indicator of academic achievement 


\section{Learning and Study Strategies Inventory (LASSI) - Weinstein \& Palmer, (2002)}

Learning and Study Strategies Inventory (LASSI) consists of 80 items assessing 10 different study strategies. There are 8 items per strategy. It assesses a students' knowledge about and application of study and learning strategies which have been shown to enhance academic success and which can be learned and applied or improved during academic interventions such as study skills program and learning strategies programs. The authors report adequate psychometric properties for the scale. Co-efficient Alpha for all except two scales (attitude and study aids) is above 0.80 . The scale appears to be reliable and valid and has been used in other studies conducted in India (Soujanya, 2006).

The 10 scales are:

The Scale for Anxiety which measures the extent to which students are concerned, anxious and worried about their academics, school and their performance in school. Lower the scores on this scale, higher is the level of anxiety experienced.

- The Scale for Attitude which measures the interest and attitude towards school and academic performance. Lower scores on this scale indicate negative attitudes.

- The Scale for Concentration and attention which measures the ability to focus and maintain concentration on academic and learning tasks. High scores reflect higher levels of attention and concentration.

- The scale for Processing of information which measures the effective use of verbal explanations, images, structuring and organizing strategies, and analytical skills to comprehend what is being learnt. Lower scores indicate poorer ability to adequate process incoming information.

- The scale for Motivation measures the will, inclination, selfdiscipline, and readiness to put in the required effort to productively accomplish learning tasks. Lower scores indicate lower levels of motivation. 
The Self-Testing Scale measures the extent of self monitoring and review of the learning process. Lower scores indicate lower levels of self reflection and self review.

The Selection of Main Ideas Scale measures the ability to identify and recognize the central idea and to separate relevant and essential information from irrelevant and less essential information. Lower scores indicate poorer ability in selecting the main ideas.

- The scale for Study Aids measures the use of extra aids, resources and supports to assist study and retain information. Lower scores indicate lower ability in effectively using study aids.

- The scale for effective Time Management measures the ability to effectively utilize available time to accomplish academic goals. Lower scores indicate poorer time management skills.

- The scale for Test taking Strategies measures the ability in using strategies for effective preparation of tests and test taking strategies. Lower scores on this scale indicate weaker test taking strategies.

The tools were group administered to the students in the classroom; common instructions were given to all the students. The approximate time taken for the completion of all the questionnaires was 60 minutes

\section{Analyses of Results and Discussion}

The responses to the questionnaires were scored as per the instructions given by the test developers. The results obtained were then subjected to appropriate statistical measures to test the stated hypotheses.

The first set of hypotheses stated that there would be significant gender differences in the Learning \& Study strategies assessed by the LASSI. The scores obtained by the boys and girls were statistically verified using independent $t^{\prime} t^{\prime}$ tests and the results are presented in Table 2. 
Table 2 showing the mean, $\mathrm{SD}$ and $\mathrm{t}^{\prime}$ ratio for the different subscales of LASSI

\begin{tabular}{|l|l|l|l|l|l|}
\hline \multirow{2}{*}{ Scales } & \multicolumn{2}{|c|}{ Boys } & \multicolumn{2}{c|}{ Girls } & \multirow{2}{*}{$\mathbf{t}^{\prime}$} \\
\cline { 2 - 5 } & Mean & SD & Mean & SD & \\
\hline Anxiety & 23.82 & 4.96 & 23.49 & 5.34 & $0.83 \mathrm{~ns}$ \\
\hline Attitude & 25.89 & 4.32 & 26.44 & 4.10 & $1.72 \mathrm{~ns}$ \\
\hline Concentration & 25.94 & 3.64 & 25.55 & 4.02 & $1.32 \mathrm{~ns}$ \\
\hline Information processing & 25.34 & 5.36 & 26.81 & 4.87 & $3.73^{\text {** }}$ \\
\hline Motivation & 26.66 & 5.25 & 27.46 & 5.42 & $1.96^{*}$ \\
\hline Self testing & 24.75 & 5.04 & 25.30 & 4.64 & $1.46 \mathrm{~ns}$ \\
\hline Selecting main ideas & 24.79 & 3.99 & 25.43 & 3.97 & $2.09^{*}$ \\
\hline Study aids & 24.34 & 4.62 & 24.67 & 4.39 & $0.95 \mathrm{~ns}$ \\
\hline Time management & 25.41 & 3.88 & 25.28 & 3.98 & $0.43 \mathrm{~ns}$ \\
\hline Test strategies & 25.84 & 3.82 & 25.28 & 4.36 & $1.80 \mathrm{~ns}$ \\
\hline
\end{tabular}

$* * \mathrm{p}<0.01 ; * \mathrm{p}<0.05 ; \mathrm{ns}=$ non significant

The results presented in Table 2 indicate that the ' $t$ ' ratios are statistically significant for three strategies: Processing of information, level of Motivation and Selection of central ideas. These results indicate that boys and girls significantly differ on these scales with

Girls showing better use of verbal explanations, imagery, structuring and organizing strategies, and analytical skills to comprehend what is being learnt.

- Show higher levels of motivation, will self discipline when studying and

- Are better able to recognize the central and main information and seperate the essential from the non essential bits of information.

However on the other seven strategies studied, no significant gender differences merged. These results are in consonance with those cited by Lightbody et.al (1996) \& Slotte, Lonka \& Ylänne (2001) who did report gender differences on a few study strategies, specifically explicit use of study strategies, especially for note taking, by girls.

Pearson's product moment correlations were computed to study the relationship between academic achievement and the different 
learning and study strategies and to prove hypothesis 2 . The results are presented in table 3

Table 3 showing the product-moment correlation between the sub scales of LASSI and Academic achievement

\begin{tabular}{|l|l|}
\hline Scale & Academic Achievement \\
\hline Anxiety & $0.10^{* *}$ \\
\hline Attitude & $0.15^{* *}$ \\
\hline Concentration & $0.15^{* *}$ \\
\hline Information processing & $0.05 \mathrm{~ns}$ \\
\hline Motivation & $0.06 \mathrm{~ns}$ \\
\hline Self testing & $0.05 \mathrm{~ns}$ \\
\hline Selecting main ideas & $0.10^{* *}$ \\
\hline Study aids & $0.01 \mathrm{~ns}$ \\
\hline Time management & $0.08^{* *}$ \\
\hline Test strategies & $0.10^{* *}$ \\
\hline
\end{tabular}

$* * \mathrm{p}<0.01 ; \mathrm{ns}=$ non significant

The results presented in Table 3 reveal that the following sub scales of LASSI viz., anxiety, attitude, attention and concentration, selection of central ideas, effective time management and self test strategies are positively and significantly related to academic achievement. These results imply the following:

- student's who do not worry about their school and their performance in school do well in academics,

- those who show an interest towards school and academic success do well in academics

- those who have the capability to focus and sustain concentration on the learning task do better in their academics

- Those who can recognize the central idea of what is being learnt and segregate the essential from the non-essential thus paying more attention to significant information do better in academics

- Those who show effective scheduling \& appropriate time management skills accomplish better in academics 
- Those who are adept at the application of strategies for test preparation and test taking strategies do well in academics

Anzi \& Owayed (2005) and Verma (1996) in their studies had also revealed that academic performance did correlate with the use of specific study strategies.

\section{Conclusions}

The results of the research indicate:

- Gender differences exist in the use of the following Learning and Study strategies - processing of information, motivation and selection of central ideas; with females scoring higher on all the three strategies.

- Academic achievement was significantly related to anxiety, concentration, attitude, selection of central ideas, self test strategies and effective time management. These results can give indicators as to what strategies should be taught in academic skills training, as these have an impact on academic achievement.

\section{References}

Anzi El \& Owayed, F. (2005). Academic Achievement and its relationship with anxiety, self - esteem, optimism and pessimism in Kuwaiti students. Social Behavior and Personality: An International Journal, 33(1), 95-104.

Barbara, S., Slate, J. R. Jones, C. H. (1999). Study behaviors of college preparatory and honors students in the ninth grade. The high school journal, 82(3), 16

Gall, M. D., (1990). Tools for learning: Study skills. A guide to teaching study skills. Association for Supervision and Curriculum Development Publishing Co. p209

Lightbody, P., Siann, G., Stocks, R. \& Walsh, D (1996). Motivation and Attribution at Secondary School: the role of gender. Educational Studies, 22(1), 13 - 25.

Slate, J. R., Jones, C. H., \& Dawson, P. (1993). Academic skills of high school students as a function of grade, gender, and academic track. The High School Journal, 76, 245-251. 
Slotte, V., Lonka, K., Ylänne, L .S. (2001) Study-strategy use in learning from text. Does gender make any difference? Instructional Science, 29(3), 255-272.

Soujanya, P. (2006). Metacognition: Styles, Correlates and strategies for intervention. Doctoral thesis submitted to Bangalore University.

Synder. (1999 - 2000). The relationship between learning styles/multiple intelligences and academic achievement of high school students. The high school journal, 83 (2), Dec. 1999 - January 2000

Verma, B. P., (1996). Test of Anxiety and Study habits: A study of their main and interaction effects on Academic Achievement. Indian Journal of Applied. Psychology, 33(2): 55-61.

Weinstein, C. \& Palmer, D. (2002). LASSI user's manual for those administering the learning and study strategies inventory (2nd ed.). Clearwater, FL: $\mathrm{H}$ and $\mathrm{H}$ Publishing Co.

Weinstein, C. E., Schulte, C., \& Palmer, D. H. (1987). Learning and Study Strategies Inventory. Clearwater, FL: Hemisphere.

Yip., Michael, C.W., Chung., Olive, L.L. (Feb 2005). Relationship of study strategies and academic performance in different learning phases of higher education in Hong Kong. Educational Research and Evaluation, 11(1), 61-70 